Cite this: Polym. Chem., 2014, 5, 3719

\title{
Thermoresponsive polymerized gemini dicationic ionic liquid
}

Received 31st December 2013 Accepted 8th February 2014

DOI: 10.1039/c3py01790g

www.rsc.org/polymers

\author{
Yongjun Men, Helmut Schlaad, ${ }^{\star}$ Antje Voelkel and Jiayin Yuan*
}

A new type of gemini poly(ionic liquid), poly[(1,8-octanediyl-bis(tri- $n$-butylphosphonium) 4-styrene sulfonate], was synthesized via the free radical polymerization of a dicationic ionic liquid monomer in DMF. This poly(ionic liquid) presented a lower critical solution temperature (LCST)-type phase transition in aqueous solution. Unusually this phase transition can be observed even at a concentration as low as $0.1 \mathrm{wt} \%$. Additionally, the type and concentration of external salt can influence the cloud point. Copolymerisation of this gemini dicationic ionic liquid monomer with divinylbenzene crosslinker in water led to the formation of a hydrogel, which exhibited a temperature-triggered volume change in water.

\section{Introduction}

Thermoresponsive polymers, which usually display a reversible phase transition in their solution at a specific temperature, have received major interest in the past two decades. ${ }^{1-5}$ Generally speaking, water-soluble thermoresponsive polymers are of special interest with respect to their wide applications in tissue engineering, controlling systems and sensing devices. ${ }^{6-8}$ The best known examples of these polymers are poly( $N$-isopropylacrylamide) (PNIPAM) and the poly(meth)acrylamide derivatives with hydrogen-bonding properties and hydrophobic interactions, which exhibit a lower critical solution temperature (LCST) behavior in aqueous solution. ${ }^{6,9-12}$ Except for zwitterionic polymers, like poly[3-( $N$-(3-methacrylamidopropyl)- $N, N$-dimethylammonio)-propanesulfonate], most thermoresponsive polymers themselves are nonionic in bulk.

Conventional polyelectrolytes are water-soluble polymers carrying ionizable functionalities along the polymer chain, which have a wide range of applications, such as water purification, oil recovery, pigment removal, paper making, layer-bylayer technology and so on. Environmentally responsive or smart polyelectrolytes are normally considered as $\mathrm{pH}$ or salt responsive polymers. Recent research demonstrates that strong polyelectrolytes in solution possess thermoresponsive properties. Aoshima et al. synthesized poly(vinyl ether)s with pendant imidazolium salt moieties, which presented an upper critical solution temperature (UCST) or LCST phase separation in organic solvents of specific polarity. ${ }^{13}$ By changing the anion to tetrafluoroborate in these polymers, a UCST-type phase separation in water was observed. Ritter $e$ a al. first reported that poly [1-butyl-3-vinylimidazolium bis(trifluoromethylsulfonyl)imide],

Max Planck Institute of Colloids and Interfaces, Department of Colloid Chemistry, Research Campus Golm, D-14424 Potsdam, Germany. E-mail: jiayin.yuan@mpikg. mpg.de; Fax: +49-331-5679502; Tel: +49-331-5679552 when mixed with cyclodextrin in water, showed a pseudo-LCST effect. ${ }^{14}$ The cyclodextrin ring complexed with the large-sized hydrophobic $\mathrm{Tf}_{2} \mathrm{~N}$ anion at low temperature to make the polymer soluble in water, and slipped off at high temperature returning the polymer to its hydrophobic state and making it insoluble in water again.

Homopolymers of polyelectrolytes with thermoresponsive properties in aqueous solution were first observed by Ohno's group. They initially studied an ionic liquid (IL), tetra- $n$-butylphosphonium styrene sulfonate (SS-P), which showed a LCSTtype phase transition in water. Surprisingly, polymerization of SS-P yielded a poly(ionic liquid) (PIL) exhibiting similar thermosensitive behavior. ${ }^{15,16}$ Recently, the same group synthesized another strong anionic polyelectrolyte, poly(tributylhexylphosphonium 3-sulfopropyl methacrylate), with LCST-type phase separation in water in a wide temperature range. ${ }^{17}$ Shortly before the submission of this manuscript, Diamond's group prepared copolymer thermoresponsive hydrogels from these two anionic PILs with several diacrylate crosslinkers of various length of the oligo(ethylene glycol). ${ }^{18}$ The volume transition temperature of these gels decreased with increasing gel crosslinker concentration.

In anionic PILs, the cation (such as the tetrabutylphosphonium cation) of the ILs always needs to be synthesized by careful structure design, but in cationic PILs, the corresponding anion, such as styrene sulfonate, is easily obtained from commercially available sodium salts. This means that the hydrophilicity/hydrophobicity of the anion is more easily tunable than that of the cation from a synthetic point of view. Our group synthesized the first cationic PIL, poly(tributyl-4vinylbenzylphosphonium pentanesulfonate), exhibiting a LCSTtype phase transition in aqueous solution. ${ }^{19}$ The transition temperature was variable in terms of the PIL concentration and externally added salts. These thermoresponsive PILs have demonstrated potentials as "smart" stabilizers for carbon and 
metal nanoparticles. For example, raising the temperature of a colloidal dispersion of graphene sheets or gold nanoparticles stabilized by these PILs would precipitate out the inorganic colloids at a specific and designable temperature.

The thermoresponsive behavior of PILs has a tight relationship with their chemical structures and hydrophilicity. Until now all the thermoresponsive ILs and PILs reported are monovalent ion molecules or polymers. Gemini (dimeric) ILs are made up of two monomeric ILs connected via the headgroups by a spacer that may be hydrophilic, hydrophobic, flexible, or rigid. Comparing with the corresponding monomeric IL, gemini ILs have a higher surface activity in aqueous solution, and exhibit a much lower critical micelle concentration, and a higher efficiency in reducing the oil-water interfacial tension.

PILs with gemini ions have the potential to present special phenomena due to their thermoresponsive properties. A key factor governing the LCST (and surface tension) is the polymer structure arising from the polymer-water interactions. Therefore, thermoresponsive PILs bearing gemini ions are of special interest, as they might present a different behavior from those made up of monomeric IL monomers.

In this research, we synthesized a gemini dication-based PIL by free radical polymerization in DMF. The PIL with unexpected high solubility is made up of a poly(4-styrene sulfonate) backbone and a gemini dication. This PIL in water showed a LCSTtype phase transition, tunable in terms of the polymer concentration and the externally added salts. Dynamic light scattering (DLS) measurement was employed to gain insight into the phase separation process. When synthesized in the presence of a crosslinker divinylbenzene, a thermoresponsive hydrogel was obtained.

\section{Experimental section}

\section{Materials}

All chemicals were purchased from Aldrich: tetra- $n$-butylphosphonium bromide (P-Br, 99\%), tri- $n$-butylphosphine (99\%), 1,8dibromooctane (98\%), divinylbenzene (technical grade, 80\%), sodium 4-styrene sulfonate (SS-Na, technical, $\geq 90 \%$ ), and all other chemicals (analytical grade) were used as received. 2,2'-Azobis(2methylpropionitrile) (AIBN, 98\%) was recrystallized from hexane.

\section{Synthesis of 1,8-octanediyl-bis(tri-n-butylphosphonium) dibromide (P2-Br)}

$30.3 \mathrm{~g}(0.15 \mathrm{~mol})$ of tributylphosphine and $13.6 \mathrm{~g}(0.05 \mathrm{~mol})$ of 1,8-dibromooctane and $150 \mathrm{~mL}$ dry acetone were loaded into a $250 \mathrm{~mL}$ round bottomed flask, containing a magnetic stir bar. The mixture was heated to $40{ }^{\circ} \mathrm{C}$ for $48 \mathrm{~h}$, and then precipitated into $1.5 \mathrm{~L}$ diethyl ether. The solid was filtered off and washed several times with diethyl ether. The resulting white powder was dried in vacuum oven to obtain a final yield of $30.1 \mathrm{~g}(89 \%)$.

Synthesis of 1,8-octanediyl-bis(tri-n-butylphosphonium) 4styrene sulfonate (SS-P2)

$27.06 \mathrm{~g}(0.04 \mathrm{~mol})$ of P2-Br, $20.62 \mathrm{~g}(0.1 \mathrm{~mol})$ of sodium 4-styrene sulfonate (SS-Na) and $40 \mathrm{~mL}$ water were loaded into a $250 \mathrm{~mL}$ reactor. The mixture was stirred at room temperature for $30 \mathrm{~min}$. The product was extracted 3 times with $\mathrm{CH}_{2} \mathrm{Cl}_{2}(50 \mathrm{~mL}$ $\times 3$ ). The organic phases were combined and washed with water $(25 \mathrm{~mL} \times 3)$. After solvent evaporation, the product (SS-P2) was dried at room temperature by high vacuum until constant weight (26.65 g, 75\% yield).

\section{Synthesis of poly[1,8-octanediyl-bis(tri- $n$-butylphosphonium) 4-styrene sulfonate], poly(SS-P2)}

$25 \mathrm{~g}(0.0283 \mathrm{~mol})$ of SS-P2, $98.6 \mathrm{mg}$ of $(0.57 \mathrm{mmol})$ AIBN and $30 \mathrm{~mL}$ DMF were added into a $100 \mathrm{~mL}$ flask. The mixture was sealed with a septum and deoxygenated by flushing with argon for $30 \mathrm{~min}$. The solution was stirred at $90{ }^{\circ} \mathrm{C}$ for $12 \mathrm{~h}$. The obtained poly(SS-P2) solution was dialyzed against deionized water exhaustively (molecular weight cut off: 3500 Da). After freeze-drying, $17.5 \mathrm{~g}$ of product was obtained (70\% yield).

\section{Synthesis of poly(tri-n-butylphosphonium 4-styrene sulfonate), poly(SS-P)}

The synthesis procedures and conditions were kept the same as for poly(SS-P2), using tetra- $n$-butylphosphonium bromide (P-Br) instead of $\mathrm{P} 2-\mathrm{Br}$.

\section{Measurement of the molar mass of poly(SS-P2)}

$0.5 \mathrm{~g}$ of poly(SS-P2) solution was loaded into a dialysis tube (MWCO $3500 \mathrm{Da}$ ) and dialyzed against NaCl solution (10 wt\%) for $7 \mathrm{~d}$. The $\mathrm{NaCl}$ solution was changed twice per day. Then, the tube was transferred into deionized water to remove free $\mathrm{NaCl}$ salt. Dialysis water was refreshed 10 times with an interval of $12 \mathrm{~h}$. The solution after cation exchange (PSS-Na solution) was freeze-dried to obtain a PSS-Na powder. The average molar mass of the PSS-Na was measured by aqueous size exclusion chromatography (SEC) using PSS-Na calibration: $M_{\mathrm{n}}=5270 \mathrm{~g} \mathrm{~mol}^{-1}$ (dispersity $M_{\mathrm{w}} / M_{\mathrm{n}}=3.2$ ). The number-average molar mass of the corresponding poly(SS-P2) is then calculated by

$$
\begin{aligned}
M_{\mathrm{n}}(\operatorname{poly}(\mathrm{SS}-\mathrm{P} 2)) & =[M(\mathrm{SS}-\mathrm{P} 2) / M(\mathrm{SS}-\mathrm{Na})] \times M_{\mathrm{n}}(\mathrm{PSS}-\mathrm{Na}) \\
& =2.14 \times M_{\mathrm{n}}(\mathrm{PSS}-\mathrm{Na})
\end{aligned}
$$

to be $11300 \mathrm{~g} \mathrm{~mol}^{-1}$. The cation exchange to tetra- $n$-butylphosphonium was performed applying the same procedure.

\section{Preparation of poly(SS-P2) hydrogel}

$250 \mathrm{mg}$ (2.83 mmol) of SS-P2, $37 \mathrm{mg}(0.283 \mathrm{mmol})$ of divinylbenzene, $9.69 \mathrm{mg}(0.059 \mathrm{mmol})$ of AIBN and $1 \mathrm{~mL}$ water were loaded into a $5 \mathrm{~mL}$ tube reactor. The mixture was polymerized at $80{ }^{\circ} \mathrm{C}$ for $12 \mathrm{~h}$. The gel phase was separated from the water phase during polymerization. The water in the upper layer was discarded, and the crosslinked poly(SS-P2) hydrogel was obtained at the bottom.

\section{Characterization methods}

${ }^{1} \mathrm{H}-\mathrm{NMR}$ measurements were conducted on a Bruker DPX-400 operating at $400.1 \mathrm{MHz}$ in $\mathrm{D}_{2} \mathrm{O}$ (signals referenced to $\delta$ $4.65 \mathrm{ppm}$ ). Size exclusion chromatography (SEC) with 
simultaneous UV ( $260 \mathrm{~nm})$ and RI detection was performed with $0.1 \mathrm{~N}$ aqueous $\mathrm{NaNO}_{3}$ as the eluent at a flow rate of $1.0 \mathrm{~mL}$ $\min ^{-1}$ at $25^{\circ} \mathrm{C}$. A PSS-MCX $\left(300 \times 8 \mathrm{~mm}^{2}, 10 \mu \mathrm{m}, 10^{5} \AA\right)$ column was used as the stationary phase, and the calibration was done with PSS-Na standards (PSS, Mainz, Germany). Temperature dependent UV/Vis measurements were conducted using a T70+ UV/Vis Spectrophotometer (PG Instruments Ltd, Leicestershire, England) equipped with a PTC-2 Peltier temperature controller (temperature control accuracy $\pm 0.5{ }^{\circ} \mathrm{C}$ ). The measurements were performed with aqueous polymer solutions in quartz cuvettes using an absorbance wavelength of $660 \mathrm{~nm}$; heating rate was $1{ }^{\circ} \mathrm{C} \min ^{-1}$. Dynamic light scattering (DLS) measurements were performed on an ALV/CGS-3 compact goniometer system, equipped with a $22 \mathrm{~mW}$ HeNe laser, at a fixed scattering angle of $90^{\circ}$. Heating/cooling of polymer samples in a thermostat was done in steps of $2{ }^{\circ} \mathrm{C}$ from $25{ }^{\circ} \mathrm{C}$ to $58{ }^{\circ} \mathrm{C}$. At every temperature, the first measurement was started after $600 \mathrm{~s}$ and data were accumulated for $5 \times 30 \mathrm{~s}$. Evaluation of data was done using the REPES program. ${ }^{20}$

\section{Results and discussion}

\section{Synthesis and characterization of gemini poly(ionic liquid)}

As outlined in Scheme 1, quaternization reaction of tri- $n$-butylphosphine with 1,8-dibromooctane at $40{ }^{\circ} \mathrm{C}$ in acetone was employed to prepare the quaternary phosphonium bromide compound 1,8-octanediyl-bis(tri- $n$-butylphosphonium) dibromide (P2-Br). In this structure, two phosphonium bromide units are bridged via an octyl spacer. After exchange of the bromide anion in $\mathrm{P} 2-\mathrm{Br}$ with the sulfonate in sodium 4-styrene sulfonate (SS-Na), a polymerizable gemini dicationic IL SS-P2, containing two 4-styrene sulfonate anions was obtained. The final product poly(SS-P2) used in this work was synthesized via conventional free radical polymerization of SS-P2 in DMF at $90{ }^{\circ} \mathrm{C}$ using AIBN ( $0.4 \mathrm{wt} \%$ with respect to monomer) as the initiator.

Proton nuclear magnetic resonance $\left({ }^{1} \mathrm{H}\right.$-NMR) spectra of these compounds in $\mathrm{D}_{2} \mathrm{O}$ (Fig. 1) were recorded to confirm the chemical structures of the products at each synthetic step. Fig. 1A displays the ${ }^{1} \mathrm{H}-\mathrm{NMR}$ spectrum of P2-Br. The methyl protons $\left(-\mathrm{CH}_{3}\right)$ at the end of the butyl chain appear at $0.9 \mathrm{ppm}$,

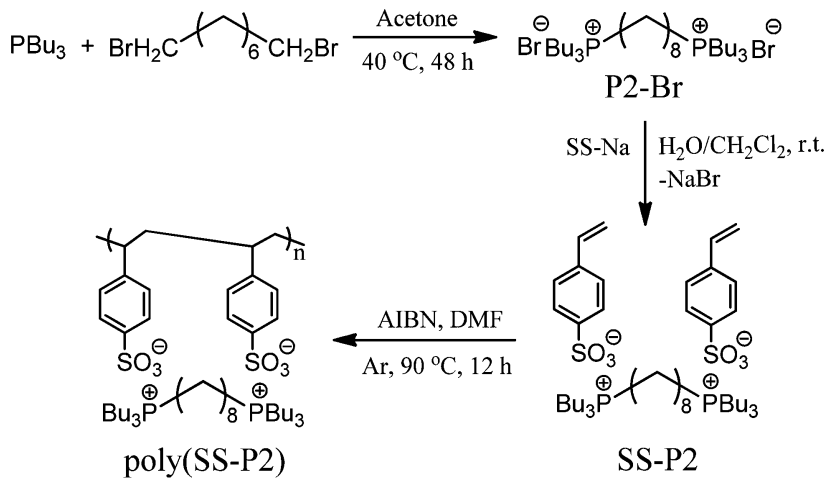

Scheme 1 The chemical structure and synthetic route to a PIL prepared from a gemini dicationic IL. SS-Na: sodium 4-styrene sulfonate.

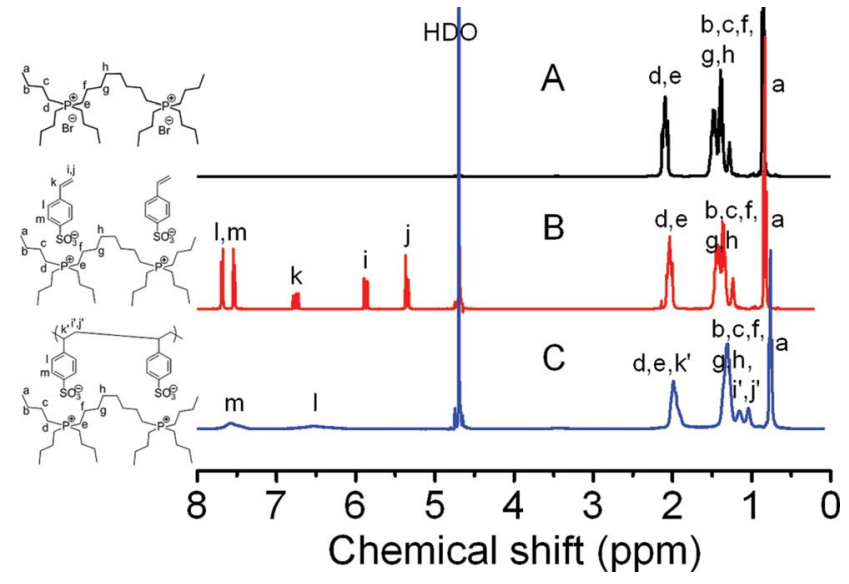

Fig. $1{ }^{1} \mathrm{H}-\mathrm{NMR}\left(400.1 \mathrm{MHz}, \mathrm{D}_{2} \mathrm{O}\right)$ spectra of $\mathrm{P} 2-\mathrm{Br}(\mathrm{A}), \mathrm{SS}-\mathrm{P} 2(\mathrm{~B})$ and poly(SS-P2) (C).

the methylene protons $\left(-\mathrm{CH}_{2}-\right)$ next to the phosphonium at $2.0 \mathrm{ppm}$, and all other methylene protons at 1.2-1.6 ppm. After anion exchange to incorporate the sulfonate anion, the peaks of the alkyl chains at $0.8-2.0 \mathrm{ppm}$ on the phosphonium cation are not affected (Fig. 1B). The newly introduced peaks are attributed to the 4-styrene sulfonate anion, namely the phenyl ring peaks at 7.6 and $7.7 \mathrm{ppm}$, and the well-resolved three vinyl proton signals at 5.4, 5.9, and $6.7 \mathrm{ppm}$. The integral ratio of the $-\mathrm{CH}_{2}$ - protons next to the phosphonium cation (d and e in Fig. 1B) to the phenyl protons ( $\mathrm{i}$ and $\mathrm{m}$ in Fig. 1B) is 2.0, identical to the theoretical value of SS-P2, which confirms the complete exchange between bromide and styrene sulfonate. Following the polymerization, the three peaks from the vinyl protons vanished, and the newly formed backbone protons overlap with the cation alkyl protons at 1.1-1.4 ppm. Thus, ${ }^{1} \mathrm{H}$-NMR spectra verify the successful synthesis of the gemini dicationic IL and the corresponding PIL.

Poly(SS-P2) was further characterized by aqueous size exclusion chromatography (SEC). Fig. 2 shows the SEC traces of poly(SS-P2), poly(SS-P), and also PSS-Na and poly(SS-P) obtained via cation exchange of poly(SS-P2) with $\mathrm{NaCl}$ and $\mathrm{P}-\mathrm{Br}$, respectively. It can be observed that the poly(SS-P2) and its cationexchanged products, PSS-Na and poly(SS-P), have almost identical elution volumes and thus hydrodynamic sizes. This may suggest that the cations of all three samples are exchanged by sodium when dissolved at $0.15 \mathrm{wt} \%$ in $0.1 \mathrm{M} \mathrm{NaNO}_{3}$ solution (eluent). Hence, the absolute number-average molar mass $\left(M_{\mathrm{n}}\right)$ of poly(SS-P2) can be calculated, based on a PSS-Na calibration, to be $11300 \mathrm{~g} \mathrm{~mol}^{-1}$ (see Experimental section), which corresponds to 25 styrene sulfonate units. Interestingly, poly(SS-P2) prepared from SS-P2 has a higher molar mass than poly(SS-P) prepared from SS-P under otherwise identical polymerization conditions. This might be caused by the dicationic monomer structure of SS-P2, having two styrene sulfonate units in very close proximity (high local monomer concentration).

\section{LCST-type phase transition behavior}

Monomer SS-P2 and poly(SS-P2) were both soluble in water at room temperature $\left(<25{ }^{\circ} \mathrm{C}\right)$ at a concentration of $2 \mathrm{wt} \%$, yet 


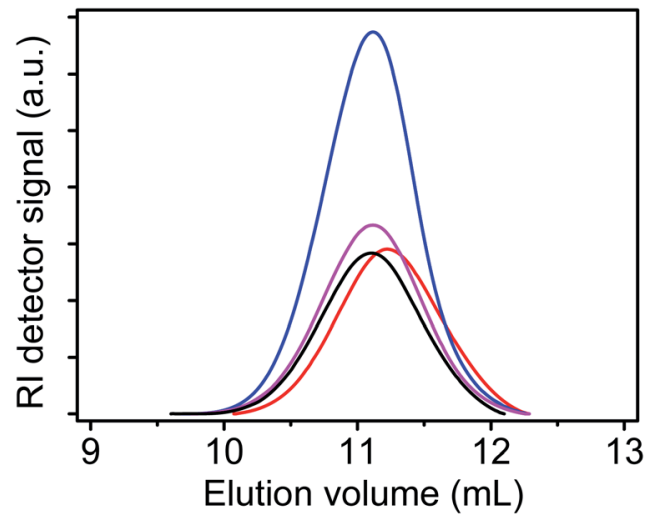

Fig. 2 SEC traces (0.1 M aqueous $\mathrm{NaNO}_{3}$, RI) of poly(SS-P2) prepared by polymerization of SS-P2 (black), poly(SS-P) by polymerization of SS$\mathrm{P}$ (red), PSS-Na via cation exchange of poly(SS-P2) with $\mathrm{NaCl}$ (blue), and poly(SS-P) via cation exchange of poly(SS-P2) with $\mathrm{P}-\mathrm{Br}$ (magenta).

solutions turned turbid upon heating. Ultraviolet-visible (UVvis) spectroscopy (operated at $\lambda=660 \mathrm{~nm}$ ) was employed to determine the cloud point temperatures $\left(T_{\mathrm{cp}}\right)$, defined here as the temperature at which transmission dropped to $80 \%$. The turbidity curves of SS-P2 (Fig. 3) show that the $T_{\text {cp }}$ increases upon dilution: $T_{\mathrm{cp}}=6{ }^{\circ} \mathrm{C}$ (at $\left.2 \mathrm{wt} \%\right), 33{ }^{\circ} \mathrm{C}(1 \mathrm{wt} \%)$, and $37{ }^{\circ} \mathrm{C}$ ( $0.5 \mathrm{wt} \%)$. The $T_{\mathrm{cp}}$ is higher than the boiling point of water at an even lower concentration of $0.2 \mathrm{wt} \%$. It should be noted that at $2 \mathrm{wt} \%$, the $T_{\mathrm{cp}}$ value is $26^{\circ} \mathrm{C}$, lower than for its corresponding mono-cation IL, tetra- $n$-butylphosphonium 4 -styrene sulfonate (SS-P), at the same concentration, as reported previously. ${ }^{16,21}$ Evidently, connecting two phosphonium cations into a gemini dication strongly influences the solution and phase separation behavior.

Concentration-dependent cloud point temperatures, i.e. phase transitions, were also observed for poly(SS-P2), see Fig. 4A. The $T_{\text {cp }}$ increases from $35{ }^{\circ} \mathrm{C}(10 \mathrm{wt} \%)$ to $38{ }^{\circ} \mathrm{C}(2 \mathrm{wt} \%)$ and further up to $51{ }^{\circ} \mathrm{C}(0.1 \mathrm{wt} \%)$, hence the $T_{\mathrm{cp}}$ variation is more sensitive at lower concentrations. The phase transition is always sharp and hysteresis is very narrow, e.g. just $0.8^{\circ} \mathrm{C}(2 \mathrm{wt}$ $\%)$ and $0.4{ }^{\circ} \mathrm{C}(0.5 \mathrm{wt} \%)$ (Fig. 4B). The values for poly(SS-P2) are

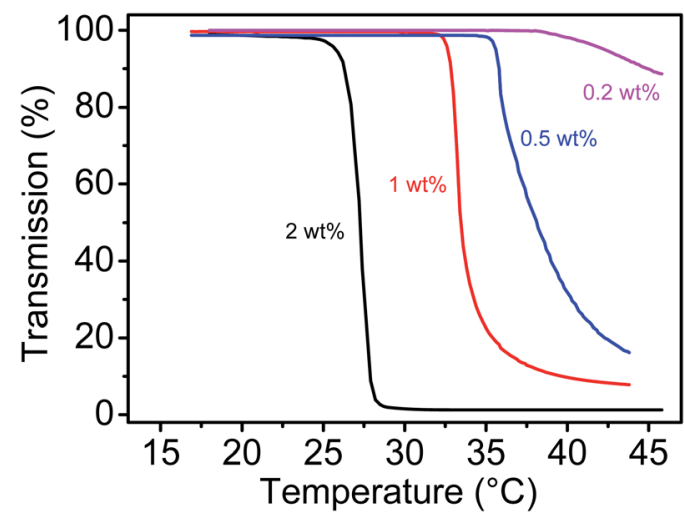

Fig. 3 Turbidity curves of SS-P2 at concentrations of 2 wt\% (black), $1 \mathrm{wt} \%$ (red), $0.5 \mathrm{wt} \%$ (blue), and $0.2 \mathrm{wt} \%$ (magenta) in water. thus significantly lower than for poly(SS-P), made up of the monovalent IL monomer. ${ }^{21}$ Notably, poly(SS-P2) exhibits a higher phase separation temperature $\left(43^{\circ} \mathrm{C}\right.$ at $\left.0.5 \mathrm{wt} \%\right)$, i.e. it is more hydrophilic, than the monomer SS-P2 $\left(36^{\circ} \mathrm{C}\right.$ at $\left.0.5 \mathrm{wt} \%\right)$. It appears that the shielding of hydrophobic styrene units from the water phase is better achieved in a polymer chain structure rather than in a (non-aggregated) monomer.

Turbidity measurements can only detect macroscopic phase separations, that is when the agglomerates are already very large $(>1 \mu \mathrm{m})$ and/or concentration (density) is sufficiently high. For insights into the transformation processes on the nanometer level, we conducted temperature-dependent dynamic light scattering (DLS) measurements. Results, i.e. hydrodynamic radii $\left(R_{\mathrm{h}}\right)$ of particles, for poly(SS-P2) at 0.1 and $0.5 \mathrm{wt} \%$ in water are displayed in Fig. 5. At room temperature, both (optically clear) solutions contain molecularly dissolved polymer chains as well as a tiny fraction $\left(<0.1 \%\right.$ in number) of aggregates with $R_{\mathrm{h}}<100 \mathrm{~nm}$. Upon heating, the primary soluble aggregates continually grow. For the $0.5 \mathrm{wt} \%$ solution, a sudden increase of aggregate size from $180 \mathrm{~nm}$ to $>600 \mathrm{~nm}$ occurs at $44^{\circ} \mathrm{C}$. This temperature is close to the $T_{\mathrm{cp}}\left(43^{\circ} \mathrm{C}\right)$ as determined by turbidity measurement. At higher temperatures a decrease in aggregate size is observed which is due to the sedimentation of the particles out of the scattering volume. For the more dilute sample ( $0.1 \mathrm{wt} \%)$, on the other hand, DLS only detects a continuous growth of
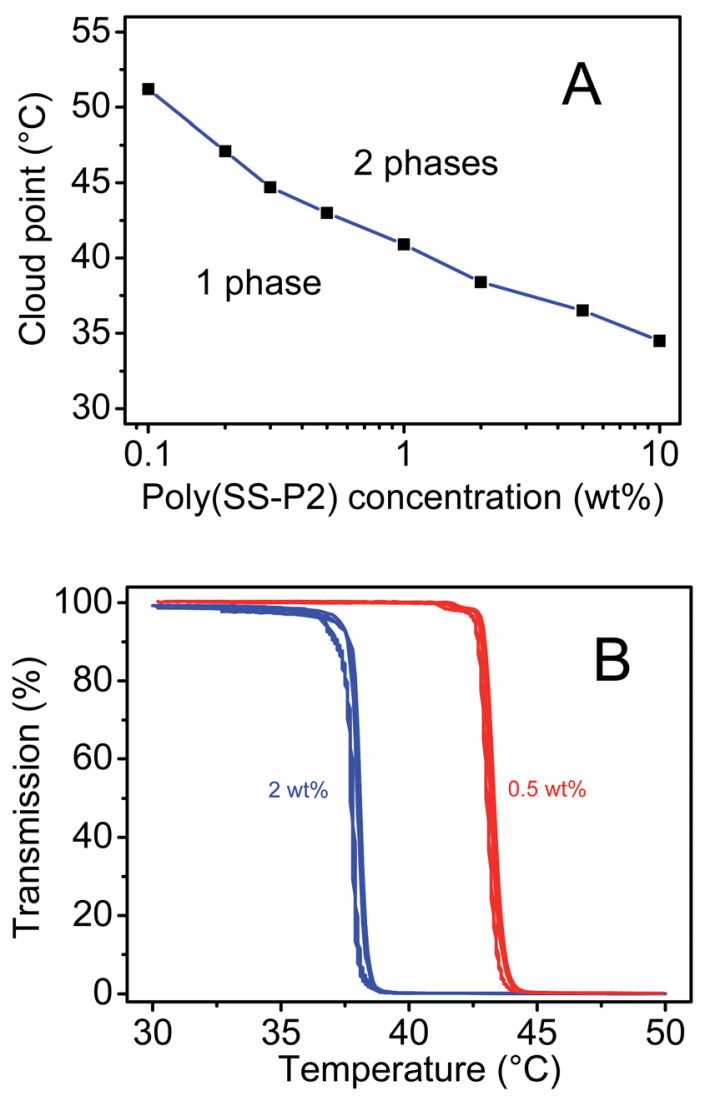

Fig. 4 (A) Plot of the cloud point temperature vs. poly(SS-P2) concentration. (B) Turbidity curves of poly(SS-P2) at 2 wt $\%$ (blue) and $0.5 \mathrm{wt} \%$ (red) in water for 3 cycles. 


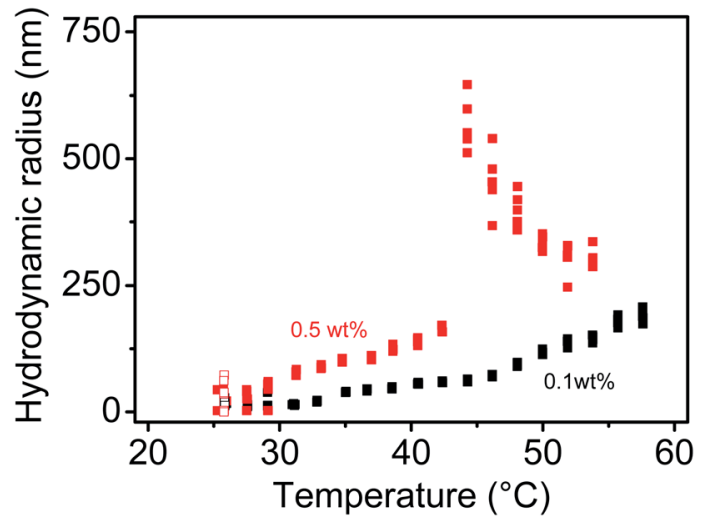

Fig. 5 Hydrodynamic radii $\left(R_{\mathrm{h}}\right)$ of particles of poly(SS-P2) at $0.1 \mathrm{wt} \%$ (black) and 0.5 wt\% (red) in water as detected by temperaturedependent DLS measurements; closed symbols = heating cycle, open symbols $=$ cooling cycle.

particles and no sharp transition until $60^{\circ} \mathrm{C}$. The $T_{\mathrm{cp}}$ of this sample as determined by turbidity measurement is $51{ }^{\circ} \mathrm{C}$, corresponding to an aggregate size of $130 \mathrm{~nm}$ in Fig. 5. Here, the aggregates, though stable in solution, are large enough to scatter the visible light and turn the original solution to a turbid dispersion. Upon cooling back to room temperature, both samples clear again. The solutions contain molecularly dissolved chains and small aggregates, as before, demonstrating the reversibility of the phase transition.

It has earlier been observed that the addition of foreign salts can shift the $T_{\mathrm{cp}}$ of thermoresponsive PILs in a wide range. ${ }^{21}$ Normally, $T_{\mathrm{cp}}$ will increase upon adding more hydrophilic salts and decrease upon adding more hydrophobic salts. For instance, the $T_{\mathrm{cp}}$ of a solution of poly(SS-P) increases upon the addition of $\mathrm{KBr}$ and decreases upon the addition of $\mathrm{P}-\mathrm{Br}$ due to different hydrophobicity of the cations. Ohno et al. ${ }^{17}$ also demonstrated that a buffer solution containing $\mathrm{KH}_{2} \mathrm{PO}_{4} /$ $\mathrm{K}_{2} \mathrm{HPO}_{4}$ could decrease the $T_{\mathrm{cp}}$ of another anionic PIL, poly(tributylhexylphosphonium 3-sulfopropyl methacrylate). In the present system, the gemini dication-based poly(SS-P2) shows a similar behavior. Fig. 6A depicts the turbidity curves of the aqueous solution of poly(SS-P2) at $0.5 \mathrm{wt} \%$ at various concentrations of KBr. The $T_{\mathrm{cp}}$ of poly(SS-P2) increases from $43{ }^{\circ} \mathrm{C}$ to 46 ${ }^{\circ} \mathrm{C}$ at a very low $\mathrm{KBr}$ concentration of about $0.01 \mathrm{M}$, and further increases to $55^{\circ} \mathrm{C}, 64{ }^{\circ} \mathrm{C}$ and $73{ }^{\circ} \mathrm{C}$ for $[\mathrm{KBr}]=0.1 \mathrm{M}, 0.2 \mathrm{M}$ and $0.3 \mathrm{M}$, respectively. At all these conditions, the turbidity curves dropped sharply at their $T_{\mathrm{cp}}$. No clouding, i.e. $T_{\mathrm{cp}}>95^{\circ} \mathrm{C}$, is observed at $0.5 \mathrm{M} \mathrm{KBr}$.

Other salts like SS-P2, P2-Br, and P-Br were also applied at the same polymer concentration (Fig. 6B). Addition of the more hydrophobic gemini diphosphonium $\left(\mathrm{P}^{2+}\right)$ cation lowers the $T_{\text {cp }}$ more effectively than the tetra- $n$-butylphosphonium $\left(\mathrm{P}^{+}\right)$ cation, for instance to below $31{ }^{\circ} \mathrm{C}$ at $0.02 \mathrm{M}$ SS-P2. In fact, the addition of $\mathrm{P}-\mathrm{Br}$ seems to have no effect on cloud point temperature due to a balanced contribution between the anion exchange effect and salting out effect. From this point of view the solution behavior of poly(SS-P2) can be varied via the choice of salt additives (like the Hofmeister salt effect). ${ }^{6}$
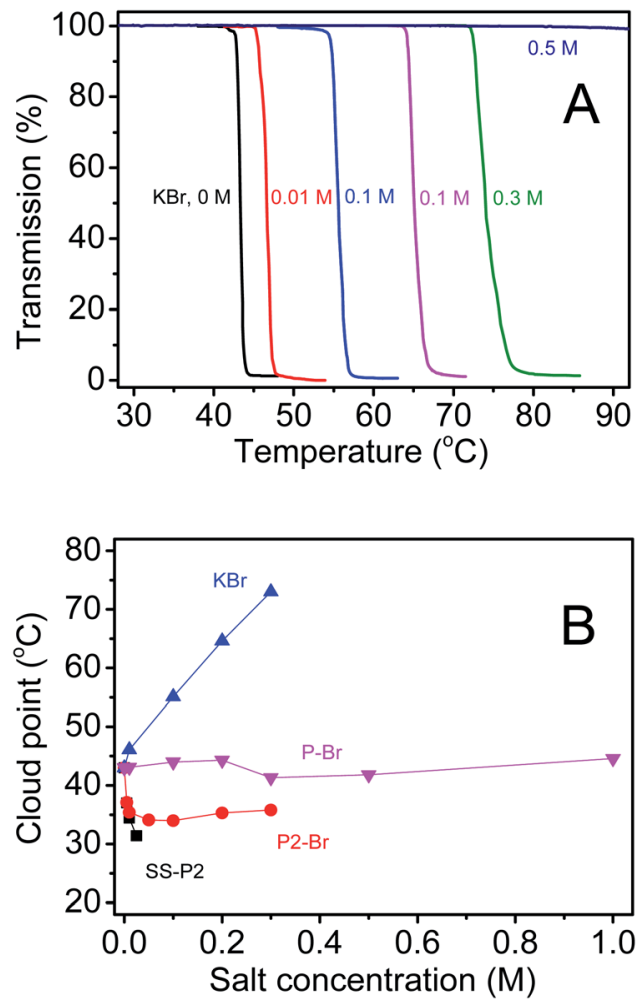

Fig. 6 (A) Turbidity curves of poly(SS-P2) at $0.5 \mathrm{wt} \%$ in aqueous solution in the presence of different concentrations of $\mathrm{KBr}$. (B) Plots of the cloud point temperatures vs. salt concentration for $\mathrm{KBr}$ (blue), $\mathrm{P}-\mathrm{Br}$ (magenta), P2-Br (red), and SS-P2 (black).

\section{Thermoresponsive hydrogel}

It was expected (or hoped) that the polymerization of SS-P2 in DMF would produce a gel, the chains being crosslinked by ionic interactions through the gemini diphosphonium cation. Possible explanations for the failure of crosslinking could be the low degree of polymerization (25) and the dynamic ionic bonding between the PSS backbone and the P2 dication. A poly(SS-P2) gel could be produced by polymerization of SS-P2 using divinylbenzene (10 mol\% with regard to SS-P2 monomer) as crosslinking agent and AIBN as initiator in water at $80^{\circ} \mathrm{C}$. At this high temperature and concentration, SS-P2 separates from water forming a two-phase mixture ( $c f$. Fig. 3 ) and polymerization proceeds under heterophase conditions. The produced poly(SS-P2) gel, which settles at the bottom of the reaction vessel, is dialyzed against water for $72 \mathrm{~h}$ (to remove unreacted monomer), isolated, and dried in vacuum $\left(1 \times 10^{-3} \mathrm{mbar}\right)$ at $100{ }^{\circ} \mathrm{C}$.

The water content in the hydrogel was determined to be $92.4 \mathrm{wt} \%$. The solid content in the gel is $7.6 \mathrm{wt} \%$, a concentration at which the $T_{\mathrm{cp}}$ of poly(SS-P2) should be around $36{ }^{\circ} \mathrm{C}$ (very close to human body temperature). Considering the hydrophobic divinylbenzene fraction, the $T_{\mathrm{cp}}$ is expected to drop even below $36^{\circ} \mathrm{C}$. However, the transformation temperature of the hydrogel state was recognized to be $45^{\circ} \mathrm{C}$ (Fig. 7). It appears that the polymer chains in a crosslinked state might have a different physical environment from the free polymer 

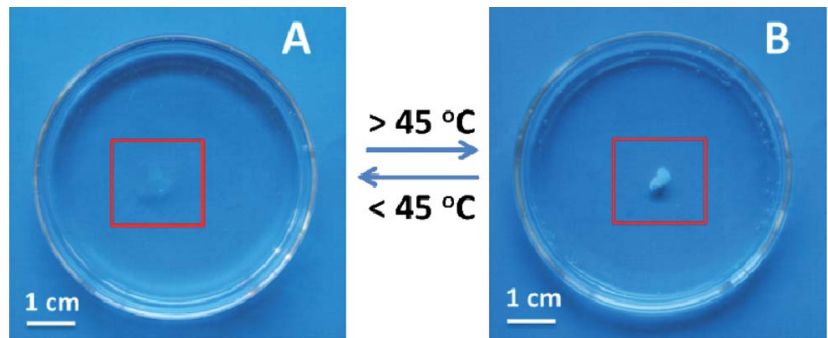

Fig. 7 Crosslinked poly(SS-P2) hydrogel in water at (A) below $45^{\circ} \mathrm{C}$ and (B) above $45^{\circ} \mathrm{C}$.

chains in solution. Crosslinking of poly(SS-P2) chains, however, seems to increase the cloud point temperature.

\section{Conclusion}

Soluble poly[1,8-octanediyl-bis(tri- $n$-butylphosphonium) 4-styrene sulfonate] (poly(SS-P2)) was synthesized via free radical polymerization of the IL monomer SS-P2 in DMF. This polymer contains a PSS backbone and a gemini quaternary diphosphonium cation. In aqueous solution it shows a LCST-type phase transition, which is tunable in terms of polymer concentration and externally added salts. Uniquely, this polymer shows a detectable cloud point $\left(T_{\mathrm{cp}}\right)$ at a rather low concentration $(0.1 \mathrm{wt} \%)$ and a very narrow hysteresis $\left(<1{ }^{\circ} \mathrm{C}\right)$, which has not been observed in previously reported PILs with a LCST-type phase transition. A thermoresponsive poly(SS-P2) hydrogel could also be prepared with the aid of divinylbenzene as crosslinking agent.

\section{Acknowledgements}

The authors thank the Max Planck Society for financial support. YM would like to acknowledge a scholarship from the China Scholarship Council.

\section{Notes and references}

1 M. A. C. Stuart, W. T. S. Huck, J. Genzer, M. Muller, C. Ober, M. Stamm, G. B. Sukhorukov, I. Szleifer, V. V. Tsukruk,
M. Urban, F. Winnik, S. Zauscher, I. Luzinov and S. Minko, Nat. Mater., 2010, 9, 101-113.

2 I. Dimitrov, B. Trzebicka, A. H. E. Müller, A. Dworak and C. B. Tsvetanov, Prog. Polym. Sci., 2007, 32, 1275-1343.

3 E. S. Gil and S. M. Hudson, Prog. Polym. Sci., 2004, 29, 11731222.

4 C. Weber, R. Hoogenboom and U. S. Schubert, Prog. Polym. Sci., 2012, 37, 686-714.

5 J. W. Robinson, C. Secker, S. Weidner and H. Schlaad, Macromolecules, 2013, 46, 580-587.

6 N. ten Brummelhuis, C. Secker and H. Schlaad, Macromol. Rapid Commun., 2012, 33, 1690-1694.

7 D. Roy, W. L. A. Brooks and B. S. Sumerlin, Chem. Soc. Rev., 2013, 42, 7214-7243.

8 Y. Zhang, S. Furyk, D. E. Bergbreiter and P. S. Cremer, J. Am. Chem. Soc., 2005, 127, 14505-14510.

9 E. Karjalainen, N. Chenna, P. Laurinmaki, S. J. Butcher and H. Tenhu, Polym. Chem., 2013, 4, 1014-1024.

10 N. Weber, J. Texter and K. Tauer, Macromol. Symp., 2011, 302, 224-234.

11 J. Niskanen, C. Wu, M. Ostrowski, G. G. Fuller, S. Hietala and H. Tenhu, Macromolecules, 2013, 46, 2331-2340.

12 Y. Men, M. Drechsler and J. Yuan, Macromol. Rapid Commun., 2013, 34, 1721-1727.

13 H. Yoshimitsu, A. Kanazawa, S. Kanaoka and S. Aoshima, Macromolecules, 2012, 45, 9427-9434.

14 S. Amajjahe and H. Ritter, Macromolecules, 2008, 41, 32503253.

15 Y. Kohno and H. Ohno, Aust. J. Chem., 2011, 64, 15601567.

16 Y. Kohno and H. Ohno, Aust. J. Chem., 2012, 65, 91-94.

17 Y. Kohno, Y. Deguchi and H. Ohno, Chem. Commun., 2012, 48, 11883-11885.

18 B. Ziolkowski and D. Diamond, Chem. Commun., 2013, 49, 10308-10310.

19 Y. Men, H. Schlaad and J. Yuan, ACS Macro Lett., 2013, 2, 456-459.

20 J. Jakes, Collect. Czech. Chem. Commun., 1995, 60, 17811797.

21 Y. Men, X.-H. Li, M. Antonietti and J. Yuan, Polym. Chem., 2012, 3, 871-873. 